\title{
Personajes veterotestamentarios en el Evangelio de Juan
}

\author{
Josep Oriol Tuñí, \\ Facultad de Teología de Catalunya, \\ Centro de Reflexión Teológica, San Salvador.
}

En el tema de la relación entre el Evangelio de Juan y el Antiguo Testamento, hay un capílulo relativamente reducido que puede ser abarcado en una breve presentación: el de los personajes de las tradiciones veterotestamentarias utilizados en el texto para iluminar los episodios de la vida de Jesús. Se trata de pocos personajes (Abraham, Jacob, José, Moisés, Isaias, Elías) y de sucintas referencias genéricas a los patriarcas y a los profetas.

En primer lugar haremos una sencilla presentación de los fragmentos más relevantes para sacar después alguna consecuencia de cara a la lectura y comprensión del Anliguo Testamento en el Evangelio de Juan. Porque, sorprendentemente, este sencillo tema nos da una modesta, pero al mismo tiempo profunda, vía de acceso a la lectura del Evangelio de Juan y a la integración del Antiguo Testamento en la comprensión de las tradiciones cristianas del siglo I'.

1. Personajes relevantes de las tradiciones del Antiguo Testamento en el Evangelio de Juan

Es de sobras conocido que, además de los personajes mencionados más anriba, los exegetas han encontrado en el Evangelio de Juan claras referencias a Isaac en la presentación de Jesús como cordero de Dios y también en la muerte de Jesús como verdadero cordero pascual ${ }^{2}$. No obstante, tenemos que prescindir de esta imagen porque no es aceptada por todos. También es objeto de discusión si Juan 1,51 hace referencia o no a la tradición del Génesis $(28,12)$ sobre la escalera del suefio de Jacob ${ }^{3}$. En todo caso, este texto no resulta demasiado relevante para nuestra investigación. Nos limitaremos, por tanto, a analizar brevemente los textos que presentan las figuras de Abraham, Jacob (y José), Moisés e Isalas y haremos una referencia a la figura de Elías. 
a) Abraham. Veamos en primer lugar el papel de la figura de Abraham. Es suficientemente conocido que Abraham sólo aparece en el capítulo 8 del Evangelio de Juan. La función de Abraham en este fragmento es muy peculiar y caracteristica del Evangelio de Juan. Por una parte se amolda a lo que dicen las tradiciones judías: es el padre de los judios ("nosotros tenemos a Abraham como padre", 8, 39), al que apelan cuando se sienten atacados en su preeminencia ("nosotros somos descendientes de Abraham y no hemos sido nunca esclavos de nadie", 8, 33), o cuando piensan que se cuestiona su identidad más profunda ("nuestro padre es Abraham", 8, 39).

Jesús acepla la referencia a Abraham en su discusión con los judlos sobre la libertad y la filiación, pero interpreta de otra manera su significación. Tras reconocer que los judios son descendencia de Abraham ("ya sé que son descendencia de Abraham", 8, 37); sin embargo, les recrimina el que no hacen las obras de Abraham ("si son ustedes hijos de Abraham, hagan las obras de Abraham", 8, 39). Ahora bien, parece claro que, según el Evangelio de Juan, la obra de Abraham por excelencia es la fe. La referencia a la fe del patriarca no puede pasar desapercibida. Lo que Jesús recrimina a los judios en el fragmento de 8, 31-59 es su falta de fe: lo muestra suficientemente el hecho de que se refiera repetidamente a su incapacidad de escuchar su palabra ("mi palabra no se abre camino en el interior de ustedes", 8, 37; "no pueden ustedes escuchar mi palabra", 8, 43). Pero lo muestra lambién la inequívoca referencia al comportamiento homicida de los judíos ("me quieren matar", 8, 37.40). Y, por encima de todo lo explicitan las afirmaciones sobre la falta de fe ("no creen en mr", 8, 45; "porque no me creen", 8,46$)^{4}$.

Ahora bien, hay en este fragmento un dato que resulta bastante sorprendente: parece que la obra de Abraham mencionada no es la fe genérica del patriarcas. Es más en concreto la fe en Jesús. En efecto, Abraham es presentado como el que ha visto el dia del Mesías y se ha alegrado por ello $(8,56)$. No interesan para nuestra breve y sencilla investigación los detalles de esta sorprendente referencia y su telón de fondo en las tradiciones bíblicas y extrabiblicas (numerosos y bastante sugerentes) ${ }^{6}$. Conviene remarcar que, en cierto sentido, se da una clara preeminencia de Jesús por encima de Abraham: Abraham ve el día de Jesús y se alegra por ello $(8,56)$. Ahora bien, esta preeminencia llega hasta la formulación capital, que cierra dramáticamente la escena ("antes que apareciese Abraham, yo existo", 8, 58). El contraste entre el aparecer (el nacer) de Airraham y la realidad de Jesús que permanece para siempre no puede ser pasado por alı: "antes de que Abraham llegase a existir, yo existo"7. Quizás de entre todas las autoproclamaciones de Jesús en el Evangelio de Juan ésta es la más profunda y la que más se adentra en la realidad de Jesús en tanto que es objeto de la confesión de la comunidad.

De este primer texto podernos sacar pues una conclusión: Jesús está por

Digitalizado por Biblioteca "P. Florentino Idoate, S.J."

Universidad Centroamericana José Simeón Cañas 
encima de Abraham no solamente en el sentido de ser más importante que el patriarca, sino sobre todo porque la preeminencia de Jesús le sitúa en un nivel que sobrepasa el momento histórico de Abraham. Jesús, por decirlo de alguna manera, es anterior a Abraham. Tiene un nivel de realidad que lo hace superior y anterior a Abraham. Pero también hay otra implicación: la realidad de Jesús tiene vigencia en el tiempo de Abraham. El tiempo de Abraham se hace presente y acual en el tiempo de Jesús. No parece que la figura de Abraham sea presentada con las características de ser un typos de Jesús. Más bien parece que se subraya una relación vigente y actual entre Abraham y Jesús. Volveremos más adelante sobre este punto.

b) Jacob. La figura de Jacob aparece sólo en un texto del Evangelio de Juan. Se urata de la conocida y familiar conversación de Jesús con la mujer de Samaria. El texto parece implicar también que Jesús es más grande que Jacob, en el sentido de que puede dar el agua que lleva a la vida eterna $(4,5.6 .12$; véase 7 , 37-39 y 19, 34). La pregunta de la samaritana está formulada en términos de pretensión: ¿acaso tú eres superior a Jacob?, y parece exigir una respuesta negativa (en griego, mê...). La pregunta tiene un claro paralelo con el fragmento de Abraham: ¿acaso ú eres superior a Abraham? $(8,53)$. Y, de hecho, el diálogo de Jesús con la samaritana llevará a la autoproclamación de Jesús: "soy yo, el que habla contigo" $(4,26)$. La pregunta de la mujer es sobre la identidad mesiánica de Jesús (¿el mesías samaritano?). La respuesta, en cambio, parece ir más allá: "ni en esta montaña ni en Jerusalén...". La realidad de Jesús parece situar el culvo en otro nivel.

Ahora bien, lo que sorprende en este texto es que Jacob no parece ser presentado directamente como typos de Jesús, sino que el acento está en que es inferior a Jesús. La función de la figura de Jacob en el Evangelio de Juan parece apuntar en la misma dirección que la de Abraham: Jesús puede dar una agua que est́́ en otro nivel, un agua que da vida para siempre. Esta es el agua verdadera que Jesús puede dar. Esto Jacob no lo podia hacer".

En cualquier caso tenemos que retener la preeminencia de Jesús en relación no sólo a Jacob sino también —así parece implicarlo el texto- a su hijo José, que aparece como objeto de la donación del pozo por parte de su padre. La presencia de José resulta mucho menos definida e importante.

c) Moisés'. Moisés ocupa un lugar de una cierta importancia en el Evangelio de Juan. Los textos que hablan del patriarca son bastante relevantes. Para nuesura limitada investigación, habrá suficiente con recordarlos y quedarnos con la función que más parece iluminar nuestra búsqueda.

Los textos son muy conocidos: 1,$17 ; 1,45 ; 3,14 ; 5,45-46 ; 6,32 ; 7,19-23$; 9, 28-29 (véase 8, 5). Haremos una referencia directa a los tres primeros que, de alguna manera, contienen los rasgos más importantes para nuestra investigación. A raiz de estos tres textos $(1,17 ; 1,45 ; 3,14)$, los otros textos serán recordados 
y aplicados.

El primer texto se encuentra en el prólogo ("la ley se dio a través de Moisés; en cambio la gracia y la fidelidad se han hecho realidad en Jesús", 1, 17). Parece bastante claro que se trata de un texto añadido al himno al $\operatorname{Logos}^{10}$. El contraste es fuerte y a pesar de que no hay, por lo que parece, voluntad de oposición radical o exclusiva", no obstante la preeminencia de la gracia (plenitud del tiempo mesiánico) y de la fidelidad por encima de la Ley es bastante clara.

El hecho de que Moisés hubiese dado la Ley es conmemorado también en 7, 18-19: "Moisés les dio la Ley, pero nadie cumple esta Ley". Este segundo texto parece relativizar no sólo la ley, sino también la función de mediador del don de la ley: lo que hizo Moisés no llega a ser eficaz. La figura de Moisés, como las de Abraham y Jacob, parece ser notablemente inferior a Jesús. Como si estuviese en otro nivel. Ahora bien, la tipología tampoco parece ser aqul el punto de mira del autor. Difícilmente podríamos decir que Moisés aparece en el Evangelio de Juan como rypos de Jesús. En cualquier caso, Jesús, en el Evangelio de Juan, no es un nuevo Moisés ${ }^{12}$. En efecto, el texio que menciona a Moisés en el capítulo 9 pone una vez más a Moisés en contraposición con Jesús: los seguidores de Jesús son claramente contrapuestos a los discípulos de Moisés ("tú eres el discípulo de aquél, nosotros somos discípulos de Moisés. Y sabemos que Dios habló a Moisés; éste en cambio no sabemos de dónde es", 9, 28-29). La vigencia de Moisés es importance, al menos para el Judarsmo del tiempo en que se puso por escrito el evangelio ${ }^{13}$.

El segundo texto que tenemos en el Evangelio de Juan sobre Moisés hace referencia a la presentación de Jesús a Natanael por parte de Felipe, que nos sitúa en una confesión de fe bien clara ("aquél sobre el cual escribieron Moisés en la ley y también los profetas, lo hernos encontrado, es Jesús el hijo de José, de Nazaret", 1, 45). Resulta interesante la formulación "aquél sobre el cual escribió Moisés...". Moisés es presentado como el que escribe sobre Jesús y, por tanto, le conoce. Más aún, el contenido de la Ley es Jesús. Este rasgo será remarcado mís adelante cuando Jesús mismo diga "Moisés escribió sobre mr" $(5,45)$. La Ley, pues, tiene como contenido esencial la realidad de Jesús. Por ssto Moisés es, en el fondo, para la comunidad del Evangelio de Juan, un acusador nás que un defensor de los judíos. Pero, en realidad, es un testimonio de Jesús "ustedes escudrifian las Escrituras porque creen que en ellas hay vida eterma; ues bien, ellas da testimonio sobre min ${ }^{2}, 5,39$ ). La interpretación joannea de la igura de Moisés es aquí muy positiva y muy vigente.

El tercer texto resulta también interesante ("de la misma manera que Moisés evantó la serpiente en el desierto, conviene que el Hijo del hombre sea levantalo de la tierra, para que todo el que crea en el tenga vida eterna", 3, 15. Parece jue tenemos aqui una referencia a Números $21,4-9$, donde el pueblo es curado ie la picadura de las serpientes a través de la mirada alzada hacia la serpiente de 
bronce que Moisés hace y coloca sobre un estandarte. La tradición judia subraya que no era la serpiente la que curaba de las picaduras (Sab 16, 6-7) ${ }^{14}$.

Ahora bien, el término de la comparación del Evangelio de Juan no es aquí Moisés que levanta la serpiente. El punto de referencia, como señala con acierto la exégesis, es triple: la elevación, su virtud salvífica y el designio latente de Dios (dei, conviene que..., es necesario que...). Desde el punto de vista tipológico o alegórico el lếrmino de comparación no es Moisés; más bien parece ser el "ser elevado" o "ser levantado" o, Lodavia, el "ser exalıado" y su acción salvífica"s . Estamos ante un concepto imporlante en la Teología del Evangelio de Juan: ser exaltado significa, al mismo tiempo, ser elevado en la cruz ("cuando ustedes habrán exaltado al Hijo del hombre", 8, 28) y ser llevado al mundo de la gloria ("ser glorificado")'. En todo caso, para nuestra breve investigación, el protagonismo de Moisés parece estar aquí subordinado al del gesto de la exaltación ${ }^{17}$. Y ciertamente que en esta imagen no encontramos un eco tipológico: como mucho, Moisés es implícilamente comparado con los judíos.

Con estos tres textos hemos podido percibir el tono fundamental del papel de Moisés en el Evangelio de Juan. De entre los aspectos mencionados hay uno que no solamente sitúa a Moisés por debajo de Jesús, sino que remarca que Moisés escribió sobre Jesús. ¡La importancia y la preeminencia de Jesús resulta patente! Pero, además, el texto explicila que Moisés no solamente conoce a Jesús, sino que escribe sobre Jesús: el mero centro del Antiguo Testamento (de la tradición del Pentateuco) es Jesús. Esto sitúa a Jesús por encima de Moisés, pero al mismo liempo remarca una relación directa entre Moisés y Jesús. Sobre esto volveremos más adelante.

d) Isaías. Digamos finalmente una palabra sobre la figura de Isafas. También Isaias es referido a Jesús con una peculiaridad que resultará aclarada en los textos targúmicos, pero que en el texto del Evangelio de Juan deja entrever su importancia. El Evangelio de Juan cita el texto de Isaías 6, 10, utilizado también por la tradición sinóptica, y le arlade una referencia ulterior (Is 6,1 ). Se trata, como es muy conocido, de una cita importante, con variantes de una cierta relevancia $^{10}$. Recordaremos el texto y haremos un par de reflexiones en tomo a la cita en el Evangelio de Juan.

"Por esto no podian creer, como decía también Isalas: él ha cegado los ojos y les ha endurecido el corazón para que sus ojos no vean ni su corazón comprenda y no se conviertan, que yo los curaría". Isaías decía esto hablando de él (de Jesús), porque habia visto su gloria (Jn 12, 39-41).

Una primera constatación del texto es su fuerte interpretación cristológica ("y yo les curaria"). A pesar de que el texto se amolda aqui a los LXX (kai iasomai autous), no obstante la aplicación se nos da inmediatamente ("Isaĺas decía esto hablando de Jesús", 12, 41). En el talante del Evangelio de Juan la cita tiene una clara interpretación cristológica. Pero, como se sabe muy bien,

Digitalizado por Biblioteca "P. Florentino Idoate, S.J."

Universidad Centroamericana José Simeón Cañas 
aquí hay algo más. El texto recuerda que Isaías dijo esto "porque" (o "cuando según la conocida variante textual") "vio la gloria de él". Este "él", en el col texto, no es Dios sino Jesús. La referencia al Targum resulta también aq iluminadora ${ }^{20}$. Esto ha llevado a la exégesis a preguntarse de qué gloria se tra si de la del Jesús preexistente, la del Jesús terrenal o la del Jesús exaltado. I texto es mucho más radical y en el fondo mucho más directo: la gloria de Jesı parece ser una realidad sin determinaciones temporales ${ }^{21}$. Es preciso notar tar bién que no se dice si Isaías vio la gloria anticipadamente o no. Por otra parte, contemplación de la gloria de Jesús resulta un dato muy osado e importante. Pc que volvemos a encontrar el mismo esquema que hemos constatado en el trat miento de Abraham y de Moisés: hay una cierta contemporaneidad entre Isai y Jesús. Y Jesús es el contenido fundamental de la visión del profeta ${ }^{2}$. Pero, mismo tiempo, se remarca la superioridad plena de Jesús por encima de Isaías.

Hasta aquí nuestra sencilla investigación. De esta breve presentación pod mos sacar consecuencias de una cierta magnitud.

Primero, se diría que todos estos personajes (ciertamente Moisés, pero cat biên Abraham e Isalas) conocen a Jesús, y que lo conocen en profundidad. : decir que conocen el misterio de Jesús, su identidad más profunda. Saben q Jesús pertenece a la esfera de Dios: sea como contenido lundamental de las trai ciones del Pentateuco (Moisés), sea también como figura mesiánica capi (Abraham), sea finalmente en la visión de la gloria de Dios que resulta ser gloria de Jesús (Isaras). Por tanto podríamos decir que todos estos personaj tienen una clara y directa relación con Jesús.

Conviene notar también que la relación de todas estas figuras con Jesús tie una doble vertiente. Por una parte, todos son inferiores a Jesús. Este rasgo res ta especialmente claro en la afirmación repetida en el evangelio de ¡que tod esios personajes han muerto! ${ }^{23}$, dado que se presenta siempre en tensión con afirmaciones sobre Jesús ("¿acaso eres más grande que Abraham y los profe que murieron?").

Ahora bien, por otra parte, parece que hay una cierta contemporaneidad Jesús con todos ellos, a pesar de la prioridad que hernos señalado. Esto lo 1 dríamos ilustrar con un dato, exegéticamente poco elaborado pero suficien mente signilicativo: que Jesús, en la presentación que tenemos en el capíluk parece ser identificado con Elías. En efecto, la dinámica de las preguntas que enviados de Jerusalén hacen a Juan lleva a la conclusión de que en el texto $b_{\text {: }}$ del Evangelio de Juan había una clara identificación de Jesús con Elías ${ }^{24}$. E dato, que no resulta del todo inusitado (recordemos que aunque Mateo identif a Juan Bautista con Elías [Mt 11, 14], en cambio Lucas se resiste a hacerk narece imolicar aue el que tiene que venir es Jesúis ${ }^{25}$ ), sitúa a Jesús en un ni 
Así pues, si nos preguntamos qué papel juegan todas estas figuras en el Evangelio de Juan no podemos ir a caer en el esquema promesa-cumplimiento para describir la relación. En efecto, Abraham conoce el día del Mesías en su plenitud, en su realización. Moisés escribe sobre Jesús y su poder salvífico, no sobre un rasgo por especial que sea; escribe sobre la obra de Jesús y sobre el alcance salvífico de la obra de Jesús. Finalmente, Isaias contempla la gloria de Dios en Jesús; no dice el texto la gloria de Jesús preexistente ${ }^{25}$, por tanto, también la gloria del Jesús terrenal ${ }^{27}$.

Creo que una ciera conclusión se impone: en el Evangelio de Juan, el esquema que parece presidir las relaciones entre Jesús y los personajes del Anliguo Testamento, más que poder ser descrito en términos de promesa-cumplimiento, se tendría que describir en términos de contemporaneidad o de anticipación. Parece que Jesús tiene una cierta anticipación incluso temporal respecto a todos estos personajes. En este sentido no nos debe extrañar que no hayamos encontrado rasgos claros de lipología en la presentación de estos personajes. Si en algunos textos la figura del typos parece a primera vista ser iluminadora, en cambio en un análisis un poco más cercano la tipología queda fundamentalmente excluida".

¿Cómo se pueden describir, pues, las relaciones entre el Antiguo Testamento y Jesús, a la luz de los personajes que el Evangelio de Juan ha presentado para iluminar la figura de Jesús? De cara a desentrafiar este aspecto tenemos que hacer una referencia, aunque sea muy breve, a los textos que parecen hablar del cumplimiento del Antiguo Testamento en Jesús.

\section{El verbo pleroan y su uso en el Evangelio de Juan}

A primera vista el Evangelio de Juan parece amoldarse al uso del Nuevo Testamento cuando hace servir el verbo pleroûn ${ }^{29}$. Los acontecimientos de la vida de Jesús son presentados como realización o cumplimiento de lo que decían textos del Antiguo Testamento. La misma construcción gramatical así lo indica: un hina consecutivo acostumbra a introducir los textos que remarcan el cumplimiento de lugares o tradiciones veterotestamentarias $(12,38 ; 13,18 ; 15,25 ; 17$. $12 ; 19,24.36$ ).

Notemos sin embargo que en el mismo uso del verbo pleroûn hay una característica que sorprende. Porque es necesario remarcar que no sólo se cumple lo que dice la Escritura, sino que también se cumplen las palabras de Jesús ("para que se cumpliese la palabra que dijo Jesús", 18, 9; "para que se cumpliese la palabra de Jesús, sobre de qué muerte tenia que morir", 18, 32). En un cierio sentido (al menos por lo que se refiere al uso del verbo pleroûn) las palabras de Jesús son situadas al mismo nivel que el Antiguo Teslamento.

En este mismo contexto del cumplimiento del Antiguo Testamento conviene hacer una segunda consideración semántica. Al menos en un texto, el cumpli-

Digitalizado por Biblioteca "P. Florentino Idoate, S.J."

Universidad Centroamericana José Simeón Cañas 
miento de la escritura se da con una plenitud que se subraya con el verbo teleloûn. Es un texto importante porque está inmediatamente antes de la muerte de Jesús: "después de esto, Jesús, sabiendo que todo se habla realizado (hoti panta tetelestai), para que se cumpliese plenamente la Escritura (hina telisthêi hê graphê), dijo: tengo sed" $(19,28)$. Dos cosas se pueden decir al menos sobre este texto. En primer lugar, que la Escritura es puesta al mismo nivel que la vida de Jesús. En efecto, la vida de Jesús, en la medida que es realización de la voluntad del Padre, es una obra (ergon) que se lleva a término y perfección (4, 34 y 17, 4 ; véase 5, 36 con el plural erga). Llevar a término la voluntad de Dios y realizar la Escritura es lo mismo. Pero, además, el tetelestai de Jesús en la cruz $(19,30)$ remarca la plenitud de su vida terrenal como cumplimiento de la voluntad de Dios y al mismo tiempo como plena realización de la Escritura ${ }^{30}$.

Esto queda confirmado por un rasgo importante: Jesús conoce el sentido y el cumplimiento de las Escrituras, en cambio los judíos dan otro sentido a los textos del Antiguo Testamento y los discípulos no se darán cuenta del sentido de los textos hasta la glorificación de Jesús. En efecto, los comentarios que hace el evangelio a acontecimientos como la expulsión de los vendedores $(2,17.21-22)$, el grito profético de Jesús en medio de la fiesta de las tiendas $(7,37-39)$, la entrada de Jesús en Jerusalén (12, 14-16) dejan bastante claro al lector que sólo a la luz de la enseñanza del Paráclito se podrá captar el sentido de los acontecimientos que permanecen enigmáticos: enigmáticos en tanto que palabras no comprendidas del Antiguo Testamento, pero también en tanto que gestos indescifrables de Jesús. Sólo el recuerdo causado por la acción del Paráclito (14, 26) llevará a iluminar los acontecimientos con los textos bíblicos que quedaban en la penumbra. Como dice el relato de la visita al sepulcro de Jesús: "pues aún no habían comprendido la Escritura (que dice) que tenía que resucitar de entre los muertos" $(20,9)$.

Se cumple la Escritura, pero también se cumple lo que Jesús dijo y lo que Jesús hizo. Se cree en la Escritura, pero también se cree en la palabra que Jesús dijo y en el gesto que Jesús realizo. Esta luz es la fe: 2, 22; 20, 9; véase 7, 39. Por la fe se comprende lo que de otra manera permanece oscuro. Pero entonces, como ya hemos insinuado antes, hay un cierto nivelamiento entre Jesús y el Antiguo Testamento. De alguna manera, Jesús pertenece al Antiguo Testamento. Pero como hemos visto, Jesús, a pesar de que pertenece al Antiguo Testamento está por encima del Antiguo Testamento: es anterior a Abraham, es mayor que Jacob, es el objeto (de una cierta plenitud) sobre el que escribe Moisés en la ley. Jesús tiene un conocimiento de la realidad que los discípulos sólo alcanzarán después de la resurrección, con la venida del Paráclito. Este conocimiento es el que pone a los discípulos no sólo con Jesús, sino también con los personajes del Antiguo Testamento que hemos analizado un poco más arriba. Pero este conocimiento vendrá sólo con la exaltación y el don del Espíritu. Entonces se habrá alcanzado la plenitud de la le y se habrá entrado al mundo de Jesús, que es el

Digitalizado por Biblioteca "P. Florentino Idoate, S.J."

Universidad Centroamericana José Simeón Cañas 
mundo de Dios y, por tanto, el mundo del Antiguo Testamento.

Podráamos remarcar más despacio el carácter de "conocimiento" que comporta la fe y que ha sido subrayada muy a menudo en los estudios y comentarios del Evangelio de Juan ${ }^{31}$. No lo vamos a hacer, pero este rasgo que caracteriza fuertemente la presentación del Evangelio de Juan y que, hasta cierto punto, pone al mismo nivel la fe y el conocimiento, es también un aspecto que convenía remarcar en nuestra breve investigación. Porque, en el fondo, viene a confirmar que la plena captación del misterio de Jesús comporta una determinada forma de entender el Antiguo Testamento: desde el mismo Jesús.

\section{Jesús y el Antiguo Testamento}

La conclusión de lo que hemos dicho hasta aquí es que no es el Antiguo Testamento el que ilumina a Jesús. Es más bien al revés: sólo a la luz del misterio de Jesús es posible entender el Antiguo Testamento. Por tanto, nos encontramos ante un esquema en el que la consistencia del Antiguo Testamento sólo se da plenamente en Jesús. $O$, para decirlo en otras palabras, Jesús está justo en el centro del Antiguo Testamento, en la medida que es no solamente el contenido fundamental del Antiguo Testamento sino que es el centro más profundo.

Este nexo tan intrínseco entre el Antiguo Testamento y Jesús va a la par de la fe cristológica de la comunidad joannea y enlaza con la confesión de la relación única entre Jesús y Dios que tenemos en este evangelio. Esto conviene explicarlo un poco más.

En efecto, la fe de la comunidad confiesa sin ambigüedades que el Padre de Jesús es el Dios judío ("es mi Padre el que me glorifica, el que ustedes dicen 'es nuestro Dios', pero no lo conocen", 8, 54-55; véase 6, 27; 17, 3; 20, 17). Por tanto, el que se revela en Jesús es el Dios del Antiguo Testamento. Ahora bien, la comunidad joannea está enfrentada a un judaísmo agresivo, que se niega a reconocer la legitimidad de la pretensión cristológica de la misma comunidad ("te queremos lapidar por blasfemia, porque tú, siendo un hombre, te haces a ti mismo Dios", 10, 33). La pretensión de Jesús queda clarificada en el texto capital, que centra muy bien nuestro tema (" ¿acaso eres mayor que nuestro padre Abraham que murió y que los profetas que también murieron?; ¿por quién te tienes? (tina seauton poieis, 8, 53). Por tanto, en frente de una sinagoga que pretende ser la única heredera legítima del judaísmo, la comunidad joanea confiesa a Jesús como el que está con Dios desde siempre: Abraham ha contemplado el día de Jesús; Isalas ha visto la gloria de Jesús. Es decir, la comunidad confiesa que Jesús no es fruto de una veleidad de última hora. Por esto puede revelar a Dios. Pero poner a Jesús con Dios desde siempre, como aquel que pertenece a Dios por esencia, es decir también que Dios pertenece a Jesús desde siempre y para siempre. En este sentido Jesús es el que está justo en el centro 
del Antiguo Testamento y es al mismo tiempo su origen, su fuente y su plenitud.

Hay aquí un dato hasta cierto punto evidenle: la enseñanza de los textos de Abraham, de Moisés y de Isalas parece que colocan a Jesús con Dios desde siempre. Pero entonces, las cristología de estos fragmentos resulta de la misma densidad teológica que la que tenemos en el prólogo ${ }^{12}$. En esta linea conviene recordar que las conocidas figuras de la sabiduria y del Logos (probablemente reforzadas a través de las traducciones targúmicas) son suficienternente importantes en las tradiciones del Judaísmo para legitimar a Jesús de una forma definitiva. Este parece ser el mensaje fundamental del prólogo. Pero, remarquémoslo, en el prólogo ni la sabiduría ni el Logos son imágenes tipológicas de Jesús: son el mismo Jesús. En este sentido también en el prólogo Jesús es el centro del Antiguo Testamento: lo es desde siempre y como punto focal de todo lo que se dice y recuerda. El centro de la vida de la comunidad es Jesús, pero porque Jesús ies el centro de todo, no solamente del Antiguo Testamento! No deja de ser interesante ver que tanto el tratamiento de las figuras vetererotestamentarias como el llamado Prólogo del Evangelio de Juan tienen una cristología de la misma profundidad y el mismo alcance. Si tenemos en cuenta que los textos de los personajes veterotestamentarios pertenecen a tradiciones conocidas e incluso ciladas por los sinópticos, podremos apreciar más de cerca que hay aqul uno de los rasgos más profundos del Evangelio de Juan: las mismas tradiciones han sido introducidas en una confesión que va más allá de las confesiones de fe que hay en otras obras del Nuevo Testamento ${ }^{33}$. Y, por tanto, no nos hemos alejado del judaísmo a la hora de profundizar la Cristología hasta llegar a los niveles tan elevados del Evangelio de Juan. Esto creo que conviene señalarlo hoy más que hace unos años. La misma dinámica teológica de las tradiciones del Antiguo Testamento puede explicar la densidad y el alcance de la confesión que tenemos en el Evangelio de Juan. No es preciso ir a otras fuentes. Aunque quizás es necesario ampliar el punto de referencia de las tradiciones más ortodoxas (fariseas) y adentrarse en tradiciones más heterodoxas como Qumrán y las tradiciones targúmicas ${ }^{34}$.

Por tanto, una conclusión se impone con fuerza: desde el Evangelio de Juan no es posible una lectura del Antiguo Testamento que prescinda de Jesús. Más aún: sólo en Jesús encuentra el Antiguo Testamento su consistencia y plenitud. Porque en definitiva, Jesús es el contenido último y más profundo del Antiguo Testamento. Es decir, sin Jesús no hay posibilidad de comprender el Antiguo Testamento ${ }^{35}$.

Esta presentación confirma una apreciación que he hecho otras veces y que resulta capital para comprender el Evangelio de Juan: que el tiempo en la presentación joanea está subordinado a Jesús. Y que el tiempo de Jesús es importante, no en la medida que es un tiempo especial, no porque sea un tiempo más denso que el Antiguo Testamento; lo es en la medida que Jesús está presente en

Digitalizado por Biblioteca "P. Florentino Idoate, S.J."

Universidad Centroamericana José Simeón Cañas 
la comunidad, es confesado como presente y actuante y da sentido y densidad a nuesiro tiempo. Para decirlo en otras palabras: la lectura del Evangelio de Juan en dos momentos (el de Jesús y el del autor) es una lectura que tiene dos vertientes; no son dos lecturas. Porque la realidad de Jesús actualiza cualquier otro momento que, en la historia humana, pertenezca al pasado ${ }^{36}$. Y, más en concreto, tiene una profundidad y una magnitud que es capaz de hacer presente incluso lo que sobrepasa todo tiempo: en este sentido, el Evangelio de Juan nos coloca siempre ante Dios, porque "al principio existía el que es la palabra".

Por tanto, la respuesta a nuestra pregunta inicial sobre cómo ilumina nuestro terna la lectura e interpretación del Antiguo Testamento en el Evangelio de Juan, es relativamente clara, a pesar de que no resulta fácil formular con precisión. Para el Evangelio de Juan, el Anliguo Testamento no es una niñera que nos lleva de la mano a Jesús (Pablo). Tampoco es una profecía que, en el sentido popular, anuncie la realidad de Jesús antes del tiempo fijado (Mateo). No es ampoco la promesa del que tiene que venir con plenitud en un momento determinado de la historia (Lucas). Finalmente no es tampoco un conjunto de imágenes lipológicas de Jesús que sobrepasará todas las expectativas (Hebreos). El Antiguo Testamento es sencillamente Jesús ${ }^{37}$. Lo es con la misma plenitud que la actuación de Jesús en Galilea y en Judea, en los primeros años de nuestra era. Porque el Antiguo Testamento, en profundidad, tiene como contenido la realidad de Jesús: alli hay, desde el principio, el que es la Palabra Y esta Palabra que se hizo ser humano y ha permanecido entre nosotros, ya era desde siempre y será para siempre. La radicalidad de la presentación joanea encuentra en el modesto aporte que hoy hemos presentado una confirmación plena: el Evangelio de Juan sólo tiene una obsesión, "él y sólo êl".

\section{Notas}

1. Estas sencillas páginas quieren ser una modesta pero también afectrosa aportación de hornenaje al gran biblista catalán, el benedictino P. Guiu Camps. Por desgracia no dispongo del tiempo necesario para una tarea de este cariz ni he podido tener presente la literatura reciente para darle una forma académica y científicamente más afinada. No obstante, una de las cosas que hemos aprendido del P. Guiu es que otros compromisos eclesiales pueden ser más importantes que la misma tarea exegérica.

2. Además de los textos que hacen referencia al cordero de Dios (1.29.36), hay el texwo de 3,16: "...hasta entregrar a su hijo úrico" que parece responder a Genesis 22. 12; vease B. Lindars, The Gaspel of John, Londres 1972 p. 159; X. LEon Dufour, Lecture de l'evangile selon Jean Tome l, París 1988, p. 307. Para el tema del verdadero cordero, que muere en el momento del sacrificio de los corderos en el templo, hay una literarura mucho más amplia, pero no nos interesa directamente; vease R. H. Lighufoot, St. John's Gospel, Oxford, 1956, pp. 349-356. 
3. Vesase por ejemplo J. Ashton, Understanding the Fowrth Gospel, Oxford, I991, pp. 342-348.

4. Esto lo he analizado mucho mís detalladamente en La verdad os hará libres $\left(J_{n} 8\right.$, 32), Barcelona 1973, pp. 172-173.

5. Tema suficientemente conocido en el Nuevo Testamento y utilizado en textos importantes de Pablo y de Hebreos.

6. Véase por ejemplo C. K. Barreu. The Gospel according to John, Londres 2 1978, 351.352.

7. VÉase por ejemplo B. Lindars, op.c., p. 336.

8. La respuesta de Jesús profundiza la diferencia el agua que dio Jacob, como el pan de Moisés en el desierto, no quita la sed (el pan no quita el hambre). Ni la una ni el ouro están en el mismo nivel que Jesús. Véase X. Léon Dufour, Leclure..., vol. I, pp. 355.356.

9. La literarura sobre Moisés en el Evangelio de Juan es importante. Por enecima de codo hay el conocido y citado trabajo de W. A. Meeks, The Prophet-King. Moses Traditions and the Johannine Christology, Leiden 1967.

10. Véase por ejemplo R. Schnackenburg, EI Evangelio según San Juan, vol. 1, Barcelona 1980, Pp. 291-292.

11. Esto lo dice unánimemente la exégesis actual: véase por ejemplo $\mathbf{R}$. Sehnackenburg, El Evangelio..., vol I., pp. 291-292; X. LSon Dufour. Leclure..., vol. I. pp. 130-131.

12. "For John, Jesus is certainly not a new Moses": C. K. Barreth. The Gospel..., p. 169.

13. Es bien conocida la tesis de J. I. Martyn, History and Theology in the Fourth Gospel, New York 2 1967, sobre el doble momento del Evangelio de Juan: el tiempo de Jesús y el tiempo de la Escritura del Evangelio de Juan, reflejado especialmente en textos como la diseusión entre el ciego curado y los fariseos en el capíulo 9. La importancia de la figura de Moisés en la sinagoga no puede ser igrorade.

14. Las tradiciones del Rabinismo y de la primitiva literatura cristiana sobre este texto son bastante interesantes, pero no resultan necesarias para nuestra breve investigación: véase C. K. Bartelt. The Gospel..., pp. 213-214.

15. Véase por ejemplo R. Schrackenburg, El evangelio..., vol. I, pp. 445446.

16. Véase W. Thusing, Die Erhöhung und Verherrlichung Jesu im Johannesevan. gelium Münstet 21970.

17. El contraste entre este texto (kathôs Môysês) y el texto de 6,32 (ou kathôs Môysês) parece interesante y debería ser analizado un poco más. En cambio, para nuestra investigación no parece demasiado importarle.

18. Véase el arúculo de R. Schnackenburg. "In 12,39-41. La interpretación cristológica de la Escritura por parte del autor del EVJn", en la obra El Evangelio según San Juan, vol. IV, Barcelona 1987, pp. 152-162.

19. Vease por ejemplo The Greek New Testament, Londres 1966, p. 380.

20. Véase por ejemplo, C. K. Barrell, The Gaspel..., p. 432.

21. Veáse para este tema J. O. Tuñ., Jesús y el Evangelio en la comunidad jaánica, Salamanca 1987, pp. 94-100.

22. Véase el artículo de R. Schnackenburg, "In 12,3 9-41: La interpretación criscológica de la Escritura por parte del autor del EvJn", citado más arriba. 
23. Los texios tanto sobre los padres (antepasados) como sobre los profetas subrayan que han muerto: 6, 49 (hoi Pateres... apethanon); 8. 52-53: (Abraham apthanen kai hoi prophêtai...).

24. Véase J. L. Martyn, "We have found Elijah", reproducido en su obra The Gospel of John in Christian History. New York 1979, pp. 9-54, especialmente pp. 12-13.

25. El texto tan significativo de Marcos 9, 11-13 (= Mateo 17, 10-13) no tiene paralelo en Lucas. Pero también Lucas, especialmente en los primeros capítulos del libro de los Hechos, parece implicar una identificación de Jesús con "el profeta" que, de hecho, es Elías: véase Hechos 3, 12-26.

26. A pesar de lo que afirma $R$. Schnackenburg en el arículo citado.

27. Véase las páginas 94-100 de mi obra Jesús y el Evangelio en la comunidad joánica, Salamanca 1987.

28. Aunque sea sólo en una nota, es necesario hacer aquí una referencia a Juan Bautista. Le valoración de todos estos personajes veterolestamentarios parece coincidir con la confesión de Juan cuando dice y repile: ho opisô mou erchomenos emprosthen mou gegonen hoti prôtos mou ên (1, 15; véase 1,30 y compárese con 3,28 ). El uso de gegonen resulta sorprendente y enlaza con la afirnación ho opisô mov erchomenos. También puede ser un eco de la tradición que tenemos en Lucas de que Juan Bautista nació antes que Jesús ( $L$ c 1, 57-66; véase también Jn 1, 27). Ahora bien, en Juan Bautista hay: a) una relación directa con Jesús; b) una clara conternporaneidad con Jesús; c) un conocimiento de la identidad de Jesús. Todo esto rodeado por una inequívoca inferioridad respecto a Jesús. Es decir, Juan Bautista es también un testigo en favor de Jesús $(1,7.8 .15 .19)$ como to son Moisés ( 5 , 39.45.47), Abraham $(8,56)$ e Isaías (elalèsen: 12,41 ). Este punto nos enfrenta a la pregunta de si el Evangelio de Juan sinía a Juan el Bautista en el marco del Antiguo Tesatamento como lo hace con toda claridad Lucas $(16,16$, en un texto claramente diverso al de Mateo 11, 12).

29. 12,$38 ; 13,18 ; 15,25 ; 17,12 ; 18,8 ; 18,32 ; 19,24 ; 19,36$. Pero el Evangelio de Јивл también uss el verbo teleioûn y el verbo teloûn: 4,$34 ; 5,36 ; 17,4 ; 17,23 ; 19$, 28 y 19, 30. Ahora bien, se debe decir que el verbo teleioûn es utilizado para la Escritura sólo en 19, 28; en los otros textos se hace referencia a la vida de Jesús como obra del Padre.

30. Este nivelamiento entre la vida de Jesús y la Escritura se tendría que profundizar més de lo que aquí hemos hecho. Conviene, además, recordar un dato bastente significativo. El Evangelio de Juar es cualificado como el que estí escrito (gegrap. tai) en la muy indicativa conclusión de la obra: panta de gegraptai hina pisteuête (20. 31). La vida de Jesús (el cumpliniento de la la obra que el Padre le ha encomendado) se convierte en Escritura, que es también cumplimiento de la voluntad de Dios. Así se redondea la presentación que tenemos en el Evangelio de Juan.

31. Véase, por ejemplo, J. O. Tữí, La verdad..., pp. 139-147.

32. Esto no quiere implicar que los fragmenlos que hemos utilizado $(1,17 ; 1,45 ; 5$, 45-47: 8, 58; $12,40-41$ ) tengan que ser muy antiguos dentro de la tradición del Evangelio de Juan. R. Bultrnamn, Das Evangelium des Johannes, Gottingen 1968, los considera textos del evangelista, véase p. 205 , nota 5 ; p. 346, nota 6. M.E. Boismard, L'Evangile de Jean, París 1977, lo sitúa al nivel del que llama Juan IIB, es decir, en el tercer nivel literario del Evangelio de Juan, véase pp. 177.245.327-329. En wodo caso, sin embargo, suponen una profundización armónica con la cris- 
tologla del prólogo. Y esto apunta a una obra mucho más acabada de lo que algunos querrian, aunque sea en un momento bastante avanzado de su redacción.

33. Véase la nota anterior.

34. Véase para lodo esto que aquí se menciona tan de pasada y con tan poca matización, la obra de J. Ashion, Understanding the Fourth Gospel, citada más arriba.

35. J. O. Tuñí, "La salvació ve dels jueus (Jn 4, 22). Valoració del Judaïsme des del Quart Evangeli", en el volum La Paraula al servei dels homes, Barcelona 1988. pp. 123-137.

36. J. O. Tữf́, "El Quan Evangeli i el Temps", Burlletr de I'Associació BßBlica de Catalunya, Suplement 1 (1981) 71-86.

37. Es necesario notar que la interpretación del Antiguo Testamento que se deduce de lo que decimos aqui resulta muy peculiar y característica. Lo podemos ilustrar con dos breves referencias. En primer lugar, la interpretación de la tradicjón del manná que tenemos en el capítulo 6 es muy característica: el verdadero pan del cielo es Jesús (6, 3 5.38.41.48.51), y el pan que da el Padre es Jesús $(6,32.33 .50 .57)$. Por esto se niega que Moisés dé el pan $(6,32)$, y se remarca que es el Padre quien lo da $(6,32$, ien presente!). Por otro lado, la tradición de Ezequiel sobre Dios como pastor verdadero del pueblo se realiza en Jesús de una forma sorprendente: ¡Jesús hace todo lo que Dios anuncia al pueblo en Ezequiel 34! (Esta referencia la debo a Xavier Alegre.) No se puede negar que la óplica del Evangelio de Juan en la interpretación del Antiguo Testamento resulta al mismo tiempo interesante y hermenéuticamente muy unificada. 